\title{
Corrosion inhibition and thermodynamic activation parameters of Myrtus communis extract on mild steel in sulfamic acid medium
}

\author{
A.S. Fouda, ${ }^{1}$ : S.A. Abd El-Maksoud, ${ }^{2}$ M.Sh. Zoromba ${ }^{2}$ and A.R. Ibrahim ${ }^{1}$ \\ ${ }^{1}$ Department of chemistry, Faculty of Science, Mansoura University, Mansoura-35516, \\ Egypt \\ ${ }^{2}$ Department of chemistry, Faculty of Science, Port Said and King Abdulaziz University, \\ Port Said, Egypt and KSA \\ *E-mail: asfouda@,hotmail.com
}

\begin{abstract}
The effect of an aqueous extract of Myrtuis communis on the corrosion behavior of mild steel (MS) in $5 \% \mathrm{NH}_{2} \mathrm{SO}_{3} \mathrm{H}$ solution has been investigated by the following techniques: weight loss (WL), potentiodynamic polarization (PP), electrochemical impedance spectroscopy (EIS), and electrochemical frequency modulation techniques (EFM). The inhibition efficiency (IE) increased with increase in inhibitor dose and increased with rise in temperature. The thermodynamic parameters of corrosion and adsorption processes were calculated and discussed. The adsorption of this extract was found to obey Langmuir adsorption isotherm. The PP tests indicated that the extract is mixed type. The results obtained from the three different techniques were in good agreement. The morphology of the surface was analyzed and discussed.
\end{abstract}

Keywords: Myrtus, corrosion inhibition, mild steel, adsorption.

Received: April 3, 2017. Revised: August 29, 2017. Published: October 4, $2017 . \quad$ doi: $10.17675 / 2305-$ 6894-2017-6-4-4

\section{Introduction}

Sulfamic acid (amido sulfuric acid) has long been used as an industrial cleaning agent due to its remarkable property of solubilizing hard scales and most of the deposits. Furthermore, it can be used on MSs with no problem of pitting or chloride-induced stress corrosion cracking (SCC). Sulfamic acid finds application in desalination plants for cleaning demisters, heat exchangers, and cooling water systems. Optimization in the sulfamic acid treatment is desirable in terms of plant efficiency and economic considerations. However, in spite of its capability as a potential descaling and an excellent cleaner, the industrial chemical treatment is somewhat qualitative due to the lack of corrosion and dissolution data regarding sulfamic acid [1]. Sulfamic acid behaves as a strong acid in aqueous solution but the corrosion rates are significantly lower in comparison to other acids [2]. The low corrosion rates can be reduced further by the addition of corrosion inhibitors [3]. It can be used for cleaning MS with no problem of 
chloride induced SCC. Due to these formidable properties, acid cleaners based on sulfamic acid are extensively used in a large variety of household and industrial applications [4]. Accordingly, corrosion inhibitors must be injected with the sulfamic solution to avoid the destructive effect of acid on the surface of the pipe lines [5]. MS has been widely employed as a construction material for pipe work in the oil and gas production such as down-hole tubular, flow lines and transmission pipelines [6]. Several studies have been published on the use of natural products as corrosion inhibitors in different media [7-11]. Most of the natural products are nontoxic, biodegradable and readily available in adequate quantities. Various parts of the plants, seeds [12,13], fruits [14], leaves [15-17], and flowers [18-21] were extracted and used as corrosion inhibitors. The aim of the present work is to find a naturally occurring, cheap and environmentally safe substance that could be used for inhibiting the corrosion of MS. The use of such substances will establish, simultaneously, the economic and environmental goals. In this piece of research, we report the inhibition action of Myrtus extract against the corrosion of MS in $5 \% \mathrm{NH}_{2} \mathrm{SO}_{3} \mathrm{H}$ solutions.

\section{Experimental detail}

\subsection{Composition of material samples and solution}

The aggressive solution used was prepared by dilution of analytical reagent grade sulfamic acid with bi-distilled water. The stock solution (5\%) of sulfamic acid was used to prepare the desired doses of investigated compounds.

Table 1. Chemical composition (wt. \%) of the MS.

\begin{tabular}{cccccc}
\hline Element & $\mathbf{C}$ & $\mathbf{M n}$ & $\mathbf{P}$ & $\mathbf{S i}$ & $\mathbf{F e}$ \\
\hline Weight (\%) & 0.14 & 0.35 & 0.024 & 0.003 & rest \\
\hline
\end{tabular}

\subsection{Preparation of plant extract}

The extract was obtained by water infusion: a mass of about $100 \mathrm{~g}$ of dried and crushed leaves was added to a beaker containing $500 \mathrm{~mL}$ of bi-distilled water that was freshly boiled and left to sit for 30 min off the heat; this mixture was agitated sporadically. After extraction, the sample was filtered, the volume was lyophilized, and the extract was stored in a desiccator until the time of analysis. The dried plant was crushed in small pieces of 5$10 \mathrm{~mm}$ using a cylindrical crusher and extracted with bi-distilled water. The extract was left all night, then filtered through a filter paper and completed to $1000 \mathrm{ml}$ with bi-distilled water and finally stored under refrigeration in glass flasks tapered with screw plastic lid [22]. 


\section{Experimental}

\section{WL measurements}

Coupons were prepared from MS sheet specimens cut with $2.0 \mathrm{~cm} \times 2.0 \mathrm{~cm} \times 0.2 \mathrm{~cm}$ dimensions were used for WL measurements. They were abraded with emery papers (a coarse paper was used initially and then progressively finer grades were employed), degreased in acetone, rinsed with bi-distilled water, and finally dried between two filter papers and weighed. The test pieces were suspended by suitable glass hooks at the edge of the basin, and under the surface of the test solution by about $1 \mathrm{~cm}$. All chemicals were analytical-grade reagents. The experiments were carried out under non-stirred and naturally aerated conditions. The dose range of the Myrtus extract used was varied from 50 to $250 \mathrm{ppm}$, and $100 \mathrm{~mL}$ of electrolyte was used for each experiment. The addition of the Myrtus extract did not change the $\mathrm{pH}$ of the sulfamic acid solution. After different immersion time $(30,60,90,120$ and $150 \mathrm{~min})$ at temperature range $\left(25,30,35\right.$ and $\left.40^{\circ} \mathrm{C}\right)$ by immersion of MS into $100 \mathrm{ml}$ acid solution with and without various doses of inhibitors, the specimen were taken out of the test solution, rinsed with bi-distilled water, dried as before, and weighed again accurately [23]. After the specified period of time, the specimen were taken out of the test solution, rinsed with bi-distilled water, dried as before, and weighed again accurately [25]. The average WL at a certain time for each set of the five samples was taken. The WL was recorded to nearest $0.0001 \mathrm{~g}$. The WL values are used to calculate the corrosion rate $(\mathrm{CR})$ in millimeters per year $\left(\mathrm{mm} \mathrm{yr}^{-1}\right)$ by the relation:

$$
\mathrm{CR}=\frac{K \times \Delta W}{D \times A \times t}
$$

Where, $K$ is a constant and equals to $8.76 \times 10^{4}, \Delta W$ is the WL (mg), $D$ is the MS density $\left(\mathrm{g} / \mathrm{cm}^{3}\right), A$ is the exposure area of the specimen $\left(\mathrm{cm}^{2}\right)$. Also, the degree of surface coverage $(\theta)$ and $\% \mathrm{IE}$ were calculated from:

$$
\% \mathrm{IE}=\theta \times 100=\left[1-\left(\Delta W / \Delta W^{\prime}\right)\right] \times 100
$$

Where, $\Delta W$ and $\Delta W^{\prime}$ are the WL in the presence and absence of inhibitor, respectively.

\section{Electrochemical measurements}

Electrochemical experiments were performed using a typical three-compartment glass cell consisted of the MS specimen as working electrode $\left(1 \mathrm{~cm}^{2}\right)$ and the rest being covered by using commercially available epoxy resin, saturated calomel electrode (SCE) as a reference electrode and a platinum foil $\left(1 \mathrm{~cm}^{2}\right)$ as a counter electrode. The reference electrode was connected to a Luggin capillary and the tip of the Luggin capillary is made very close to the surface of the working electrode to minimize IR drop [24]. All measurements were done in solutions open to atmosphere under unstirred conditions. All potential values were reported vs. SCE. Prior to every experiment, the electrode was abraded with successive different grades of emery paper, degreased with acetone and washed with bi-distilled 
water, and finally dried. Tafel polarization curves were obtained by changing the electrode potential automatically from $(-1.2$ to $1.2 \mathrm{~V} v s$. SCE) at open-circuit potential with a scan rate of $1 \mathrm{mV} \mathrm{s}^{-1}$. The corrosion current is performed by extrapolation of anodic and cathodic Tafel lines to a point which gives $\log i_{\text {corr }}$ and the corresponding corrosion potential $\left(E_{\text {corr }}\right)$ for inhibitor free acid and for each dose of inhibitor. Impedance measurements were carried out in frequency range from $100 \mathrm{kHz}$ to $0.1 \mathrm{~Hz}$ with amplitude of $5 \mathrm{mV}$ peak-to-peak using ac signals at open-circuit potential. Before measurements, the electrode was immersed in solution for $30 \mathrm{~min}$ until a steady state was reached. The experimental impedance was analyzed and interpreted based on the equivalent circuit. The main parameters deduced from the analysis of Nyquist diagram are the charge transfer resistance $R_{\mathrm{ct}}$ (diameter of high-frequency loop) and the double layer capacity $C_{\mathrm{dl}}$. Electrochemical frequency modulation (EFM) was carried out using two frequencies 2 and $5 \mathrm{~Hz}$. The base frequency was $0.1 \mathrm{~Hz}$, so the waveform repeats after $1 \mathrm{~s}$. The higher frequency must be at least two times the lower one. The higher frequency must also be sufficiently slow that the charging of the double layer does not contribute to the current response. Often, $10 \mathrm{~Hz}$ is a reasonable limit [25]. The intermodulation spectra contain current responses assigned for harmonical and intermodulation current peaks. The larger peaks were used to calculate the corrosion current density $\left(i_{\text {corr }}\right)$, the Tafel slopes $\left(\beta_{\mathrm{c}}\right.$ and $\beta_{\mathrm{a}}$ ), and the causality factors CF-2 \& CF-3. All electrochemical measurements were performed using Gamry Instrument (PCI 300/4) Potentiostat/Galvanostat/ZRA. This includes a Gamry framework system based on the ESA 400. Gamry applications include DC105 software for potentiodynamic polarization, EIS300 software for electrochemical impedance spectroscopy and EFM 140 software for EFM measurements along with a computer for collecting data. Echem Analyst 6.03 software was used for plotting, graphing, and fitting data. To test the reliability and reproducibility of the measurements, duplicate experiments were performed in each case at the same conditions. The corrosion penetration rate $(\mathrm{CR})$ in millimeter per year $(\mathrm{mm} / \mathrm{yr})$ is calculated from the following equation [26]:

$$
\mathrm{CR}=k \times \frac{a \times i}{D \times V}
$$

Where, $k$ is a constant equals to 0.00327 when expressing corrosion penetration rate in millimeter per year $(\mathrm{mm} / \mathrm{yr}), a$ is the atomic mass of $\mathrm{Fe}, i$ is the corrosion current density $\left(\mu \mathrm{A} / \mathrm{cm}^{2}\right), D$ is the density of MS $\left(\mathrm{g} / \mathrm{cm}^{3}\right)$, and $V$ is the valence entered in the Tafel dialogue box. With: $3270=10$ x [1 year (in seconds) $/ 96497.8]$ and $96497.8=1$ Faraday in Coulombs. The $\% \mathrm{IE}_{\mathrm{p}}$ was calculated from:

$$
\% \mathrm{IE}_{\mathrm{p}}=\left[1-\left(i_{\text {corr }}^{0} / i_{\text {corr }}\right)\right] \times 100
$$

Where, $i_{\text {corr }}^{0}$ and $i_{\text {corr }}$ are the corrosion current densities of uninhibited and inhibited solution, respectively. 


\section{Surface analysis}

The surface morphology and EDX analysis of MS specimens after WL measurements in $5 \% \mathrm{NH}_{2} \mathrm{SO}_{3} \mathrm{H}$ solution in the absence and presence of $250 \mathrm{ppm}$ Myrtus extract were studied using scanning electron microscope (Jeol JSM-T20, Japan) equipped with an Oxford Inca energy dispersion spectrometer system. The working sample was analyzed at five different locations to ensure reproducibility.

\section{Results and discussion}

\section{WL measurements}

The WL of MS specimens immersed into $5 \% \mathrm{NH}_{2} \mathrm{SO}_{3} \mathrm{H}$, in absence and presence of different doses of Myrtus extract, was investigated after different immersion time (30$150 \mathrm{~min})$ at different temperatures $\left(25-40^{\circ} \mathrm{C}\right)$. Only WL curves at $25^{\circ} \mathrm{C}$ are illustrated in Figure 1. The \%IE values at different temperatures are shown in Table 2. The results show that the presence of Myrtus plant extract suppresses the corrosion rate (CR) of the MS specimens in $5 \% \mathrm{NH}_{2} \mathrm{SO}_{3} \mathrm{H}$ solution. It was noted that the \%IE increase with the plant extract dose increases. The WL of MS in the blank solution was also found to be higher than those obtained for solutions of $\mathrm{NH}_{2} \mathrm{HSO}_{3}$ containing various doses of inhibitor [27]. This indicates that extract is an adsorption inhibitor for the corrosion of MS in solutions of $\mathrm{NH}_{2} \mathrm{HSO}_{3}$. In Table 2, values of the CR of MS and IE of all studied extract in various media are presented. The degree of surface coverage $(\theta)$ and \%IE were calculated using Equation 2.

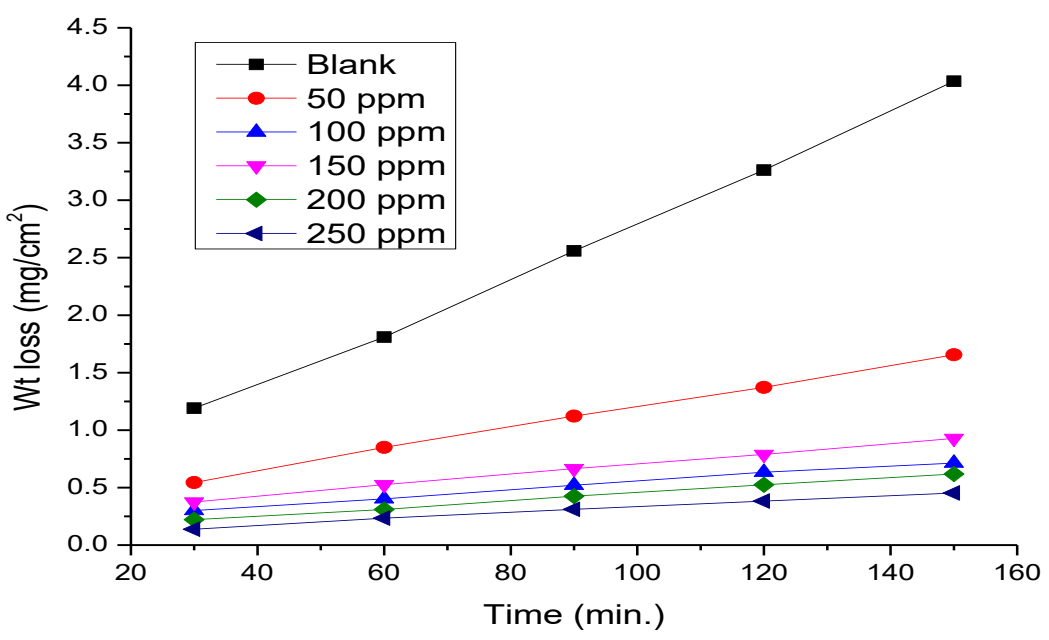

Figure 1. WL-time curve for the dissolution of MS in absence and presence of different doses of Myrtus extract extract at $25^{\circ} \mathrm{C}$. 
Table 2. The effect of different dose of Myrtus extract on the CR $\left(\mathrm{mg} \mathrm{cm}^{2} \mathrm{~min}^{-1}\right)$ and \%IE of MS in 5\% $\mathrm{NH}_{2} \mathrm{SO}_{3} \mathrm{H}$ solution at different temperatures.

\begin{tabular}{|c|c|c|c|c|c|c|c|c|}
\hline \multirow{2}{*}[C_{\mathrm{inh}}]{$(\mathrm{ppm})$} & \multicolumn{2}{|c|}{$25^{\circ} \mathrm{C}$} & \multicolumn{2}{|c|}{$3^{\circ} \mathbf{C}$} & \multicolumn{2}{|c|}{$35^{\circ} \mathrm{C}$} & \multicolumn{2}{|c|}{$40^{\circ} \mathrm{C}$} \\
\hline & C.R. & $\%$ IE & C.R. & $\%$ IE & C.R. & $\%$ IE & C.R. & $\%$ IE \\
\hline blank & 0.010 & & 0.027 & & 0.070 & & 0.133 & \\
\hline 50 & 0.005 & 48.3 & 0.011 & 57.9 & 0.039 & 44.6 & 0.064 & 52.1 \\
\hline 100 & 0.0039 & 63.9 & 0.007 & 75.8 & 0.021 & 70.8 & 0.029 & 78.6 \\
\hline 150 & 0.0031 & 68.9 & 0.005 & 80.6 & 0.014 & 79.8 & 0.021 & 84.2 \\
\hline 200 & 0.0026 & 74.4 & 0.004 & 83.9 & 0.012 & 83.6 & 0.018 & 86.8 \\
\hline 250 & 0.0019 & 80.9 & 0.003 & 88.0 & 0.007 & 90.5 & 0.013 & 90.2 \\
\hline
\end{tabular}

\section{Adsorption isotherms}

Adsorption isotherm values are important to explain the mechanism of corrosion inhibition of organo-electrochemical reactions. The most frequently used isotherms are Langmuir isotherm (Figure 2). Thermodynamic parameters for the adsorption of different inhibitors on MS surface in $5 \% \mathrm{H}_{2} \mathrm{NHSO}_{3}$ at different temperatures was listed in Table 3. From Table 3 it was found that: the negative values of $\Delta G_{\mathrm{a}}^{0}$ reflect that the adsorption of studied inhibitor on MS surface in $5 \% \mathrm{H}_{2} \mathrm{NHSO}_{3}$ solution is a spontaneous process [28]. $\Delta G_{\mathrm{a}}^{0}$ values increase (become less negative) with an increase in temperature which indicates the occurrence of endothermic process at which adsorption was favorable with increasing reaction temperature as the result of the inhibitor desorption from the MS surface [29]. It is usually accepted that the value of $\Delta G_{\mathrm{a}}^{0}$ around $-20 \mathrm{~kJ} \mathrm{~mol}^{-1}$ or lower indicates the electrostatic interaction between charged metal surface and charged organic molecules in the bulk of the solution [30]. The positive sign of $\Delta H_{\text {ads }}^{0}$ reveals that the adsorption of inhibitor molecules is an endothermic process. Generally, an endothermic adsorption process suggests either physisorption or chemisorption while endothermic process is attributed to chemisorptions [31]. Generally, enthalpy values up to $20.16 \mathrm{~kJ} \mathrm{~mol}^{-1}$ are related to the electrostatic interactions between charged molecules and charged metal (physisorption) while those around $100 \mathrm{~kJ} \mathrm{~mol}^{-1}$ or higher are attributed to chemisorption. The unshared electron pairs in investigated molecules may interact with d-orbitals of Fe to provide a protective chemisorbed film [32]. In the case of investigated compounds, the absolute values of enthalpy are relatively low, approaching those typical of physisorption. The values of $\Delta S_{\text {ads }}^{0}$ in the presence of investigated compounds are large and negative that is accompanied with endothermic adsorption process [33]. The experimental data give good curves fitting for the applied adsorption isotherm as the correlation coefficients $\left(R^{2}\right)$ were in the range $0.992-0.997 . K_{\text {ads }}$ values decrease with the increase in temperature from 
25 to $40^{\circ} \mathrm{C}$ (Figure 5). The values of surface coverage $\theta$ for different doses of the studied extract at different temperatures have been used to explain the best isotherm to determine the adsorption process. The adsorption of inhibitor molecules on the surface of MS electrode is regarded as substitutional adsorption process between the organic compound in the aqueous phase $\left(\mathrm{Org}_{\mathrm{aq}}\right)$ and the $\mathrm{H}_{2} \mathrm{O}$ molecules adsorbed on the MS surface $\left(\mathrm{H}_{2} \mathrm{O}\right)_{\text {ads }}$ [34].

$$
\mathrm{Org}_{(\mathrm{sol})}+x\left(\mathrm{H}_{2} \mathrm{O}\right)_{\mathrm{ads}} \rightarrow \mathrm{Org}_{(\mathrm{ads})}+x \mathrm{H}_{2} \mathrm{O}_{(\mathrm{sol})}
$$

Where, $x$ is the size ratio, that is, the number of $\mathrm{H}_{2} \mathrm{O}$ molecules replaced by one inhibitor molecule. Attempts were made to fit $\theta$ values to various isotherms including Frumkin, Langmuir, Temkin and Freundlich isotherms. By far the results were best fitted by Langmuir adsorption isotherm. Plotting $C / \theta$ against $C$ gave a straight line with unit slope value (Figure 2) indicating that the adsorption of extract molecules on MS surface follows Langmuir adsorption isotherm. From these results one can postulate that there is no interaction between the adsorbed species.

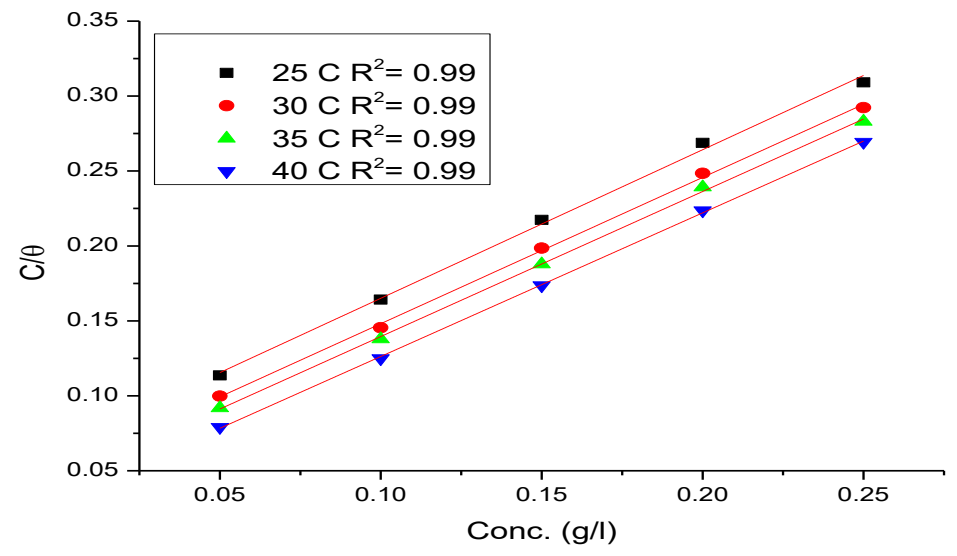

Figure 2. Curve fitting of corrosion data obtained from WL method for MS in 5\% $\mathrm{NH}_{2} \mathrm{SO}_{3} \mathrm{H}$ in the presence of different doses of the investigated plant extract to Langmuir adsorption isotherm at different temperatures.

Table 3. Adsorption parameters for MS corrosion in the absence and presence of various doses of Myrtus communis extract in $5 \% \mathrm{NH}_{2} \mathrm{SO}_{3} \mathrm{H}$.

\begin{tabular}{|c|c|c|c|c|}
\hline Temp. K & $K_{\text {ads }} \mathrm{kJ} \mathrm{mol}^{-1}$ & $\Delta G \mathrm{~kJ} \mathrm{~mol}^{-1}$ & $\Delta H \mathrm{~kJ} \mathrm{~mol}^{-1}$ & $\Delta S \mathrm{~J} \mathrm{~mol}^{-1} \mathrm{~K}^{-1}$ \\
\hline 298 & 15.16 & -17.6 & \multirow{4}{*}{20.16} & 123.65 \\
\hline 303 & 19.79 & -18.6 & & 124.75 \\
\hline 308 & 23.36 & -19.4 & & 125.05 \\
\hline 313 & 32.86 & -20.5 & & 126.84 \\
\hline
\end{tabular}




\section{Effect of temperature}

The \%IE for MS corrosion in the presence of various doses of the extract and at different temperatures was calculated and is listed in Table 2. The results of Table 2 illustrate the variation of $\mathrm{CR}$ and \%IE with extract doses at different temperatures. The obtained data revealed that the IE increased with an increase in the extract dose. This suggests that the extract species are adsorbed on the surface/solution interface where the adsorbed species mechanically form a protected film on the metal surface which inhibits the action of the corrosion. A close comparison between Tables 2 and 3 revealed that WL decreases with increasing temperature indicating that the CR decreases with increase in temperature. The value of IE was increased with rise in temperature suggesting physical adsorption mechanism [35]. These results indicate that the adsorption of investigated extract shield the metal surface at room temperature [36]. However, it may be shielded from the surface with rise in temperature. It is also clear that CR of MS in the absence and presence of extract obey Arrhenius type equation as it increases with raising solution temperature. The dependence of CR $\left(k_{\text {corr }}\right)$ on the temperature can be expressed by Arrhenius Eq. (7). The effect of temperature on the rate of dissolution of MS in $5 \% \mathrm{NH}_{2} \mathrm{SO}_{3} \mathrm{H}$ containing different doses of the investigated extract was tested by WL measurements over a temperature range from 25 to $40^{\circ} \mathrm{C}$. The effect of increasing temperature on the $\mathrm{CR}\left(k_{\text {corr }}\right)$ and \% $\%$ IE were obtained from WL measurements. The results revealed that, on increasing temperature there is an increase of $k_{\text {corr }}$ while \%IE decreases. The activation energy $\left(E_{\mathrm{a}}^{*}\right)$ of the corrosion process was calculated using Arrhenius equation [37]:

$$
k=A \exp \left(-E_{\mathrm{a}}^{*} / R T\right)
$$

Where, $k$ is the rate of corrosion, $A$ is Arrhenius constant, $R$ is the gas constant and $T$ is the absolute temperature.

Figure 3 represents Arrhenius plot ( $\left.\log k_{\text {corr }} v s .1 / T\right)$ for uninhibited and inhibited 5\% $\mathrm{NH}_{2} \mathrm{SO}_{3} \mathrm{H}$ containing different doses of the studied inhibitor. The values of $E_{\mathrm{a}}^{*}$ can be obtained from the slope of the straight lines. As in Table 4 the increase of the activation energies in the presence of extract is attributed to an appreciable decrease in the adsorption process of the extract on the metal surface with increase of temperature and a corresponding increase in the reaction rate because of the greater area of the metal that is exposed to the acid [38]. 


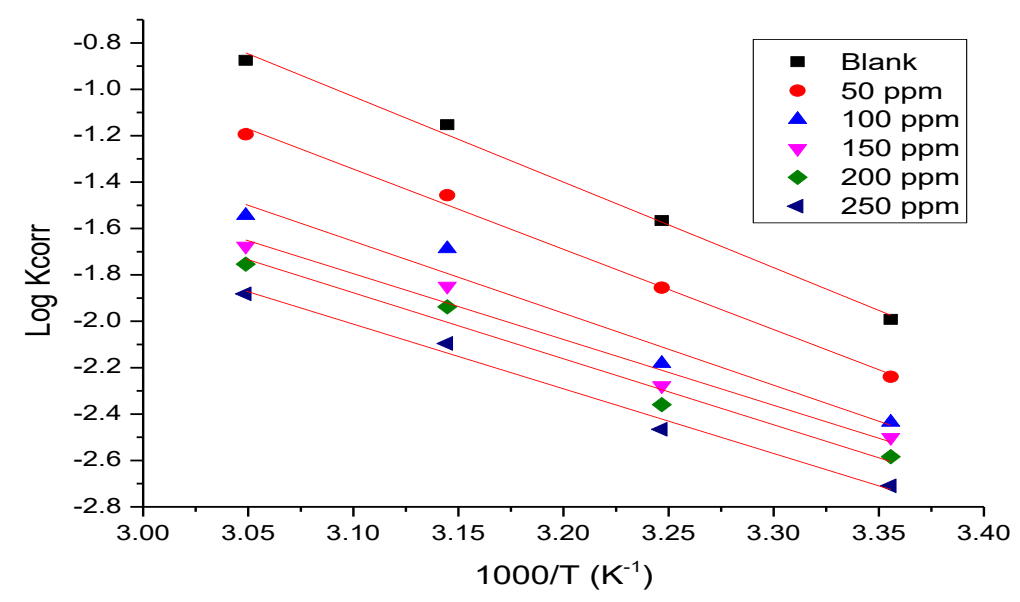

Figure 3. Arrhenius plots $(\log k v s 1 / T)$ for $\mathrm{MS}$ in $5 \% \mathrm{NH}_{2} \mathrm{SO}_{3} \mathrm{H}$ in the absence and presence of different dose of Myrtus extract.

The entropy of activation $\left(\Delta S^{*}\right)$ and the enthalpy of activation $\left(\Delta H^{*}\right)$ for dissolution of MS in $5 \% \mathrm{NH}_{2} \mathrm{SO}_{3} \mathrm{H}$ were obtained by applying the transition state equation:

$$
\log k_{\text {corr }} / T=\log \left(R / N h+\Delta S^{*} / 2.303 R\right)+\left(-\Delta H^{*} / 2.303 R T\right)
$$

Where, $N$ is Avogadro's number, $h$ is Planck's constant. A plot of $\log \left(k_{\text {corr }} / T\right) v s$. $(1 / T)$ in Figure 4 should give straight line with a slope $=\left(-\Delta H^{*} / 2.303 R\right)$ and an intercept $=$ $\log \left[(R / N h)-\left(\Delta S^{*} / 2.303 R\right)\right]$. The negative values of $\Delta S^{*}$ in the absence and presence of the inhibitors implies that the activated complex is the rate determining step and represents association rather than dissociation. It also reveals that an increase in the order takes place in going from reactants to the activated complex.

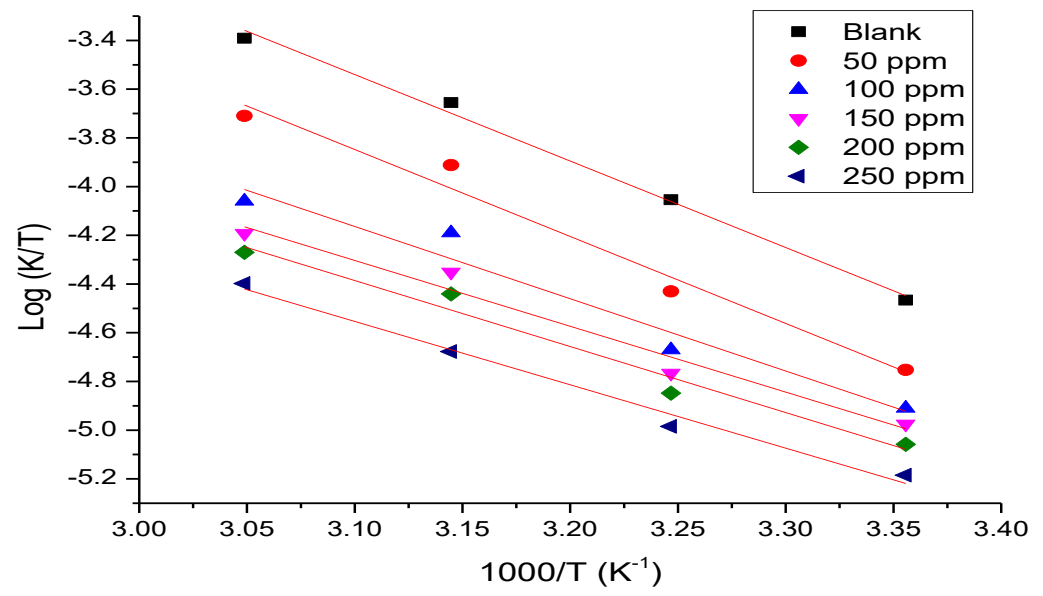

Figure 4. $\log \left(k_{\text {corr }} / T\right)$ vs. $(1 / T)$ curves for MS in the absence and presence of different doses of Myrtus extract. 
Table 3. Activation parameters for MS corrosion in the absence and presence of various doses of Myrtus communis extract in $5 \% \mathrm{NH}_{2} \mathrm{SO}_{3} \mathrm{H}$.

\begin{tabular}{|c|c|c|c|}
\hline$\left[C_{\mathrm{inh}}\right](\mathrm{ppm})$ & $\begin{array}{c}E_{\mathrm{a}}^{*} \\
\mathbf{k J} \mathbf{~ m o l}^{-\mathbf{1}}\end{array}$ & $\begin{array}{c}\Delta H^{*} \\
\mathrm{~kJ} \mathrm{~mol}^{-1}\end{array}$ & $\begin{array}{c}-\Delta S^{*} \\
\mathbf{J} \mathbf{m o l}^{-1} \mathbf{K}^{-1}\end{array}$ \\
\hline 0 & 51.4 & 20.5 & 130.3 \\
\hline 50 & 53.5 & 21.7 & 120.7 \\
\hline 100 & 54.3 & 22.7 & 119.6 \\
\hline 150 & 59.4 & 24.5 & 101.2 \\
\hline 200 & 66.2 & 28.5 & 59.3 \\
\hline 250 & 70.6 & 29.6 & 54.6 \\
\hline
\end{tabular}

\section{Potentiodynamic polarization technique}

Figure 5 shows typical anodic and cathodic Tafel polarization curves for MS in 5\% $\mathrm{NH}_{2} \mathrm{SO}_{3} \mathrm{H}$ in absence and presence of various doses of Myrtus communis. The values of cathodic $\left(\beta_{\mathrm{c}}\right)$ and anodic $\left(\beta_{\mathrm{a}}\right)$ Tafel constants were calculated from the linear region of the polarization curves. The corrosion current density $\left(i_{\text {corr }}\right)$ was determined from the intersection of the linear parts of the cathodic curves with the stationary corrosion potential $\left(E_{\text {corr }}\right)$. The percentage \%IE was calculated using the following Equation (4). Polarization measurements were carried out in order to gain knowledge concerning the kinetics of the cathodic and anodic reactions. Figure 5 presents the results of the effect of inhibitor on the cathodic and anodic polarization curves of $\mathrm{MS}$ in $5 \% \mathrm{H}_{2} \mathrm{NHSO}_{3}$. Similar curves for other compounds were obtained but not shown. It could be observed that both the cathodic and anodic reactions were suppressed with the addition of inhibitor, which suggested that these compounds reduced anodic dissolution and also retarded the hydrogen evolution reaction. Electrochemical corrosion kinetics parameters, i.e. corrosion potential $\left(E_{\text {corr }}\right)$, cathodic and anodic Tafel slopes $\left(\beta_{\mathrm{a}}, \beta_{\mathrm{c}}\right)$, and corrosion current density $\left(i_{\text {corr }}\right)$ obtained from the extrapolation of the polarization curves, were given in Table 4. The parallel cathodic Tafel curves in Figure 5 suggested that the hydrogen evolution is activation-controlled and the reduction mechanism is not affected by the presence of the inhibitor. The region between linear part of cathodic and anodic branch of polarization curves becomes wider as the inhibitor is added to the acid solution. Similar results were found in the literature [39]. The values of $\beta_{\mathrm{a}}$ and $\beta_{\mathrm{c}}$ changed slightly with increasing inhibitor dose indicated the influence of these compounds on the kinetics of metal dissolution and of hydrogen evolution. Due to the presence of some active sites, in the studied inhibitor for making adsorption, they may act as adsorption inhibitors. Being absorbed on the metal surface, these compounds controlled the anodic and cathodic reactions during corrosion process, and then their corrosion inhibition efficiencies are directly proportional to the amount of adsorbed inhibitor. The functional groups and structure of the inhibitor play important roles during 
the adsorption process. On the other hand, an electron transfer takes place during adsorption of the neutral organic compounds at metal surface [40]. As it can be seen from Table 4, the studied inhibitors reduced both anodic and cathodic currents with a slight shift in corrosion potential $(47 \mathrm{mV})$. According to Ferreira and others [41], if the displacement in corrosion potential is more than $85 \mathrm{mV}$ with respect to corrosion potential of the blank solution, the inhibitor can be seen as a cathodic or anodic type. In the present study, the displacement was $47 \mathrm{mV}$ which indicated that the studied inhibitor is mixed-type inhibitor. The results obtained from Tafel polarization showed good agreement with the results obtained from WL method. Table 4 shows the effect of the inhibitor doses on the corrosion kinetics parameters, such as $\beta_{\mathrm{a}}, \beta_{\mathrm{c}}, E_{\text {corr }}, i_{\text {corr }}$ and \%IE. From the results given in Table 4 the following observation could be drawn:

(a) The Tafel lines are shifted to more positive and negative potential for anodic and cathodic processes, respectively, relative to the blank curve. This means that the plant extract influence both cathodic and anodic processes. However, the data suggested that the inhibitor acts mainly as mixed type inhibitor [42].

(b) The inhibitor molecules found in the aqueous extract decrease the surface area available for anodic dissolution and cathodic hydrogen evolution reaction without affecting the reaction mechanism.

(c) The values of $E_{\text {corr }}$ change slowly to less negative values (i.e. nearly remain constant) and the values of $i_{\text {corr }}$ decrease.

(d) The value of IEs increases indicating the inhibiting effect of these compounds.

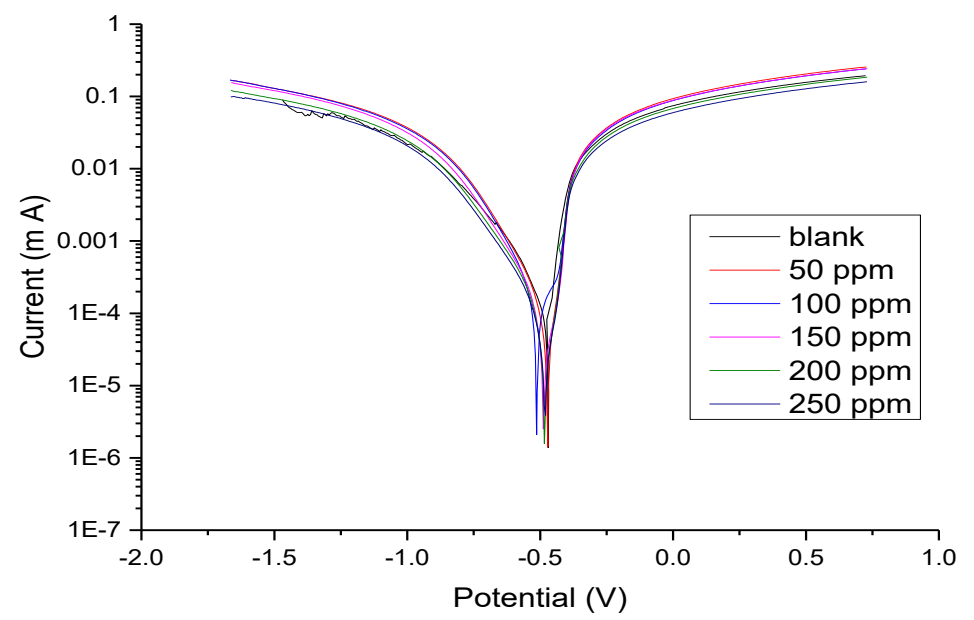

Figure 5. PP curves for the dissolution of $\mathrm{MS}$ in $5 \% \mathrm{NH}_{2} \mathrm{SO}_{3} \mathrm{H}$ in the absence and presence of different doses of Myrtus communis extract at $25^{\circ} \mathrm{C}$. 
Table 4. The effect of different dose of Myrtus extract on the free corrosion potential ( $\left.E_{\text {corr }}\right)$, corrosion current density $\left(i_{\text {corr }}\right)$, Tafel slopes $\left(\beta_{\mathrm{a}} \& \beta_{\mathrm{c}}\right), \% \mathrm{IE}$ and $k_{\text {corr }}$ for the corrosion of MS in $5 \% \mathrm{NH}_{2} \mathrm{SO}_{3} \mathrm{H}$ at $25^{\circ} \mathrm{C}$.

\begin{tabular}{ccccccc}
\hline $\begin{array}{c}{\left[\boldsymbol{C}_{\text {inh }}\right]} \\
(\mathbf{p p m})\end{array}$ & $\begin{array}{c}\boldsymbol{i}_{\mathbf{c o r r}}, \\
\boldsymbol{\mu A \mathbf { ~ c m }}\end{array}$ & $\begin{array}{c}-\boldsymbol{E}_{\mathbf{c o r r}}, \\
\mathbf{m V} \boldsymbol{\nu} \mathbf{S C E}\end{array}$ & $\begin{array}{c}\boldsymbol{\beta}_{\mathbf{a}}, \\
\mathbf{m V ~ d e c}\end{array}$ & $\begin{array}{c}\boldsymbol{\beta}_{\mathbf{c}}, \\
\mathbf{m V} \mathbf{d e c}^{-\mathbf{1}}\end{array}$ & $\begin{array}{c}\boldsymbol{k}_{\text {corr, }}, \\
\mathbf{m p y}\end{array}$ & IE\% \\
\hline 0 & 162 & 470 & 55.2 & 209.2 & 70 & \\
50 & 94.1 & 472 & 62.3 & 175.7 & 42.9 & 41.9 \\
100 & 88.5 & 454 & 42.6 & 198.8 & 40.4 & 45.4 \\
150 & 65.5 & 451 & 35.4 & 186 & 29.9 & 59.6 \\
200 & 61.3 & 447 & 31.2 & 188.9 & 28 & 62.2 \\
250 & 18.3 & 423 & 42.4 & 77.1 & 9 & 88.7 \\
\hline
\end{tabular}

\section{EIS measurements}

The corrosion of MS in $5 \% \mathrm{NH}_{2} \mathrm{SO}_{3} \mathrm{H}$ in the presence of studied plant extract was investigated by EIS method at $25^{\circ} \mathrm{C}$ after $30 \mathrm{~min}$ immersion. The impedance data of MS in $5 \% \mathrm{NH}_{2} \mathrm{SO}_{3} \mathrm{H}$ are analyzed in terms of an equivalent circuit model (Figure 6) which includes the solution resistance $R_{\mathrm{S}}$ or $R_{\Omega}$ and the double layer capacitance $C_{\mathrm{dl}}$ which is placed in parallel to the charge transfer resistance $R_{\mathrm{ct}}$ [43] due to the charge transfer reaction. The higher $R_{\mathrm{ct}}$ values are generally associated with slower corroding system [44].

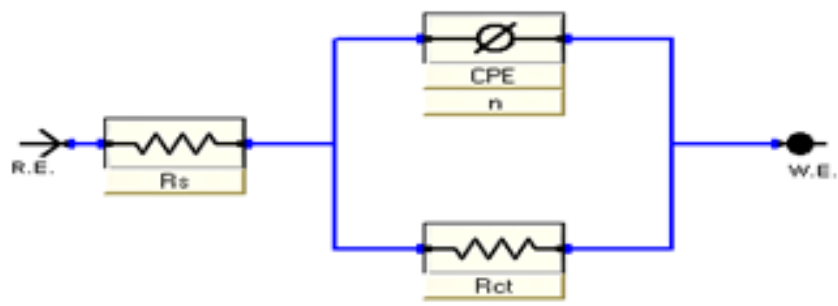

Figure 6. Equivalent circuit model used to fit the impedance spectra.

Nyquist plots in the absence and presence of investigated extract are presented in Figure 7. EIS spectra obtained consists of one depressed capacitive loop (one time constant in Bode-phase plot). The increased diameter of capacitive loop obtained in $5 \% \mathrm{H}_{2} \mathrm{NHSO}_{3}$ in presence of extract indicated the inhibition of corrosion of MS. The high frequency capacitive loop may be attributed to the charge transfer reaction. 


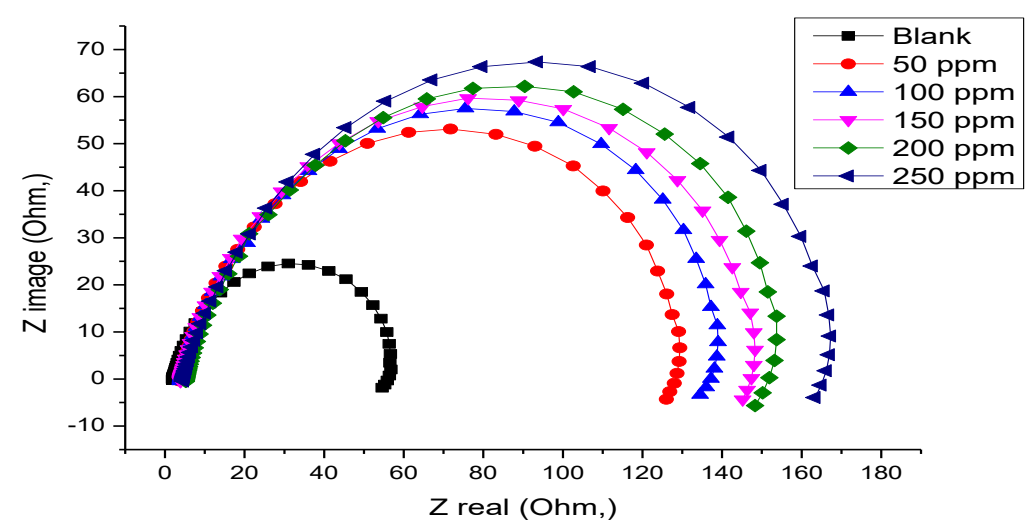

Figure 7. Nyquist plots showing effect of increasing dose of Myrtus extract on corrosion of MS in $5 \% \mathrm{NH}_{2} \mathrm{SO}_{3} \mathrm{H}$ solutions.

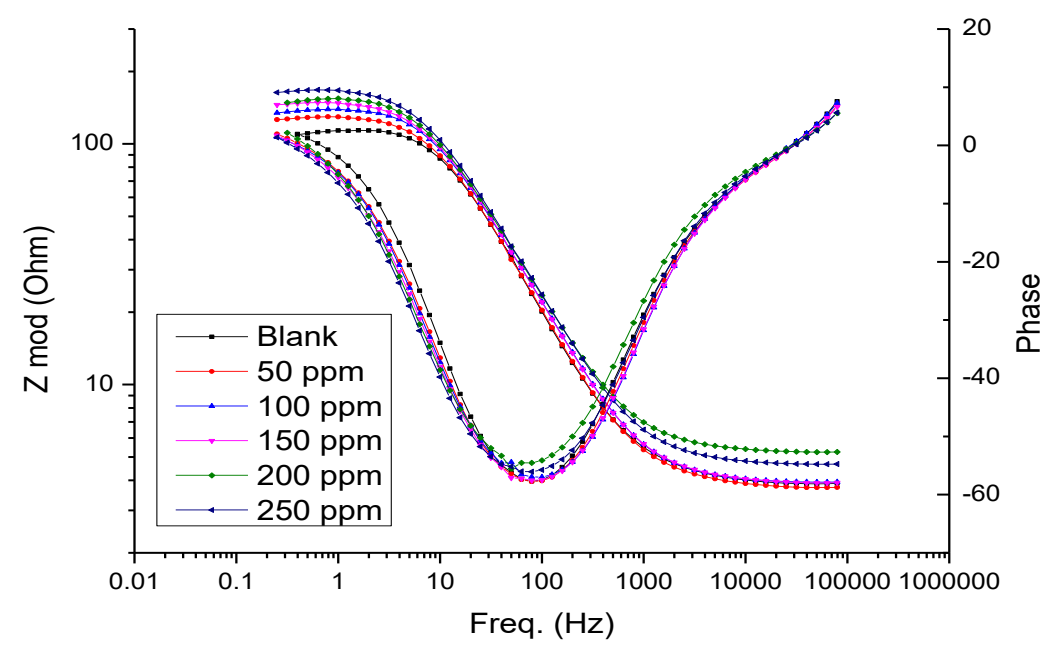

Figure 8. Bode plot for corrosion of $\mathrm{MS}$ in $5 \% \mathrm{NH}_{2} \mathrm{SO}_{3} \mathrm{H}$ in the absence and presence of different doses of Myrtus extract at $25^{\circ} \mathrm{C}$.

Corrosion kinetic parameters derived from EIS measurements and IE are given in Table 8. $C_{\mathrm{dl}}$ and $R_{\mathrm{ct}}$ were obtained from EIS measurements as described elsewhere [45]. It is apparent from Table 7 that the impedance of the inhibited system amplified with the inhibitor the $C_{\mathrm{dl}}$ values decreased with inhibitor. This decrease in $C_{\mathrm{dl}}$ results from a decrease in local dielectric constant and/or an increase in the thickness of the double layer, suggested that extract molecules inhibit the MS corrosion by adsorption at the metal/acid interface. The depression in Nyquist semicircles is a feature for solid electrodes and often referred to as frequency dispersion and attributed to the roughness and other in homogeneities of the solid electrode [46]. 
Table 5. Data from EIS measurements for corrosion of MS in 5\% $\mathrm{NH}_{2} \mathrm{SO}_{3} \mathrm{H}$ solutions at various doses of Myrtus extract.

\begin{tabular}{|c|c|c|c|}
\hline$\left[C_{\mathrm{inh}}\right], \mathrm{ppm}$ & $R_{\mathrm{ct}}, \mathrm{Ohm} \mathrm{\textrm {cm } ^ { 2 }}$ & $C_{\mathrm{dl}}, \mu \mathrm{Fcm}^{-2}$ & $\%$ IE \\
\hline 0 & 90 & 1.9 & \\
\hline 50 & 131 & 1.14 & 60.2 \\
\hline 100 & 141 & 1.12 & 63.1 \\
\hline 150 & 151 & 1.11 & 65.5 \\
\hline 200 & 160 & 1.07 & 67.4 \\
\hline 250 & 200 & 0.87 & 74 \\
\hline
\end{tabular}

In this behavior of solid electrodes, the parallel network: charge transfer resistancedouble layer capacitance is established where an inhibitor is present. For the description of a frequency independent phase shift between an applied ac potential and its current response, a constant phase element (CPE) is used which is defined in impedance representation as in Eq. (8):

$$
Z_{\mathrm{CPE}}=Y^{-1}(i \omega)^{-n}
$$

Where $Y^{0}$ is the CPE constant, $\omega$ is the angular frequency (in $\operatorname{rad~s}^{-1}$ ), $i^{2}=-1$ is the imaginary number, and $n$ is a CPE exponent which can be used as a gauge of the heterogeneity or roughness of the surface. Depending on the value of $n, \mathrm{CPE}$ can represent resistance $\left(n=0, \mathrm{Y}^{0}=R\right)$, capacitance $\left(n=1, \mathrm{Y}^{0}=C\right)$, inductance $\left(n=-1, \mathrm{Y}^{0}=L\right)$, or Warburg impedance $\left(n=0.5, \mathrm{Y}^{0}=\mathrm{W}\right)$. Figure 8 showed the electrical equivalent circuit employed to analyze the impedance spectra. Excellent fit with this model was obtained for all experimental data. The $\theta$ and \%IE were calculated using Eq. (9):

$$
\mathrm{IE} \%=\left[1-R_{\mathrm{ct}} / R_{\mathrm{inh}}\right] \times 100=\theta \times 100
$$

Where, $R_{\mathrm{ct}}$ and $R_{\mathrm{ct}}$ (inh) are charge transfer resistance values in the absence and presence of the inhibitor, respectively.

The results obtained from WL, PP, EFM, and EIS techniques are in a good agreement but it is of interest to note that, the values of \%IE given by electrochemical techniques are higher than those obtained by WL measurements; this may be due to the fact that the electrochemical measurements were carried out on freshly prepared solutions. The values of \%IE were calculated by the equation as follows:

For the Nyquist plots it is obvious that low frequency data are on the right side of the plot and higher frequencies are on the left. This true for EIS data where impedance usually falls as frequency rises (this is not true of all circuit). In the Bode plot, the impedance is plotted with $\log$ frequency on the $\mathrm{X}$-axis and both the $\log$ of absolute value of the impedance and the phase shift on the Y-axis. Unlike the Nyquist plot, the phase angle does not reach $90^{\circ}$ as it would for pure capacitive impedance. In the Bode plot at the highest 
frequencies, $\log R_{\mathrm{s}}$ appears as a horizontal plateau while at the lowest frequencies, $\log \left(R_{\mathrm{s}}+\right.$ $\left.R_{\mathrm{ct}}\right)$ appears as a horizontal plateau. The capacity of double layer $\left(C_{\mathrm{dl}}\right)$ can be calculated from the following equation:

$$
C_{\mathrm{dl}}=1 /\left(2 \pi f_{\text {max }} R_{\mathrm{ct}}\right)
$$

Where, $f_{\max }$ is the maximum frequency. The parameters obtained from impedance measurements are given in Table 5. It can be seen that the value of charge transfer resistance increases with extract dose, also the \%IE increases as the phase angle increases. The impedance study confirms the inhibiting characters of the investigated extract obtained with potentiostatic polarization methods. These observations show that the extract is adsorbed on MS surface. It is generally, assumed that adsorption at the metal-solution interface is the first step in the inhibition mechanism in aggressive acidic media. Four mechanisms have been suggested for the adsorption of organic molecules at the metalsolution interface.

\section{EFM measurements}

EFM is a non-destructive corrosion measurement technique that can directly give values of the corrosion current without prior knowledge of Tafel constants. Like EIS, it is a small signal ac technique. Unlike EIS, however, two sine waves (at different frequencies) are applied to the cell simultaneously. Because current is a non-linear function of potential, the system responds in a non-linear way to the potential excitation. The current response contains not only the input frequencies, but also contains frequency components which are the sum, difference, and multiples of the two input frequencies. The two frequencies may not be chosen at random. They must both be small, integer multiples of a base frequency that determines the length of the experiment. Figure 9 shows representative examples for the intermodulation spectra obtained from EFM measurements. Corrosion kinetic parameters are listed in Table 6. The IE values were calculated from the Equation (4). The great strength of the EFM is the causality factors which serve as an internal check on the validity of the EFM measurement. With the causality factors the experimental EFM data can be verified. The causality factors in Table 6, which are compatible with theoretical values according to the EFM theory, should guarantee the validity of Tafel slopes and corrosion current densities. The standard values for CF-2 and CF-3 are near by 2.0 and 3.0, respectively. It is quite obvious that the data obtained from chemical and electrochemical measurements were in a good agreement with the results obtained from EFM technique. 

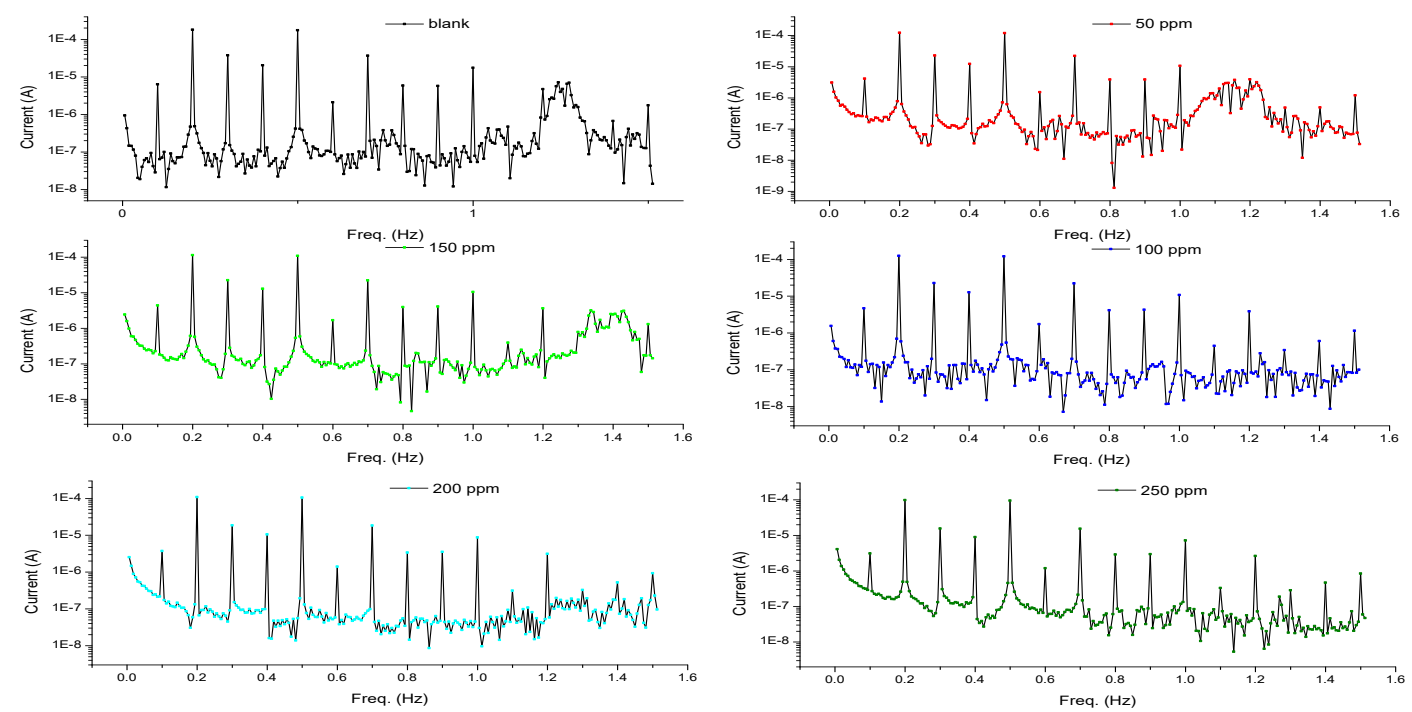

Figure 9. Intermodulation spectrum for recorded for $\mathrm{MS}$ in $5 \% \mathrm{NH}_{2} \mathrm{SO}_{3} \mathrm{H}$ in the presence of various doses (50-250 ppm) of Myrtus communis extract at $25^{\circ} \mathrm{C}$.

Table 6. Electrochemical kinetic parameters obtained by EFM technique for MS in $5 \% \mathrm{NH}_{2} \mathrm{SO}_{3} \mathrm{H}$ solutions containing various doses of the Myrtus communis extract at $25^{\circ} \mathrm{C}$.

\begin{tabular}{|c|c|c|c|c|c|c|c|}
\hline $\begin{array}{c}{\left[\mathrm{C}_{\mathrm{inh}}\right],} \\
\mathrm{ppm}\end{array}$ & $\begin{array}{c}i_{\text {corr, }} \\
\mu \mathrm{A} \mathrm{cm}^{-2}\end{array}$ & $\begin{array}{c}\boldsymbol{\beta}_{\mathbf{a}}, \\
\mathbf{m V} \operatorname{dec}^{-1}\end{array}$ & $\begin{array}{c}\beta_{c}, \\
m V \operatorname{dec}^{-1}\end{array}$ & CF 2 & CF 3 & $\begin{array}{l}\text { C.R., } \\
\text { mpy }\end{array}$ & $\%$ IE \\
\hline Blank & 356.8 & 58.07 & 225.3 & 1.96 & 2.94 & 185.1 & \\
\hline 50 & 151.4 & 55.79 & 154.7 & 1.95 & 2.89 & 69.2 & 57.57 \\
\hline 100 & 146 & 54.07 & 140 & 1.9 & 2.9 & 66.7 & 59.1 \\
\hline 150 & 136.5 & 53.5 & 155.9 & 1.9 & 2.69 & 62.4 & 61.7 \\
\hline 200 & 121 & 56.01 & 136.9 & 1.9 & 2.95 & 55.88 & 66.1 \\
\hline 250 & 95.2 & 57.7 & 132.9 & 1.9 & 2.85 & 44.45 & 73.3 \\
\hline
\end{tabular}

\section{Scanning Electron Microscopy (SEM) Studies}

The morphology of the surface of the corroded MS samples was studied using SEM after immersion in $5 \% \mathrm{NH}_{2} \mathrm{SO}_{3} \mathrm{H}$ for $12 \mathrm{~h}$. Figure 10a shows the surface of pure MS. Figure 10b,c represents the micrographs of MS in $5 \% \mathrm{NH}_{2} \mathrm{SO}_{3} \mathrm{H}$ in absence and presence of $250 \mathrm{ppm}$ of Myrtus communis extract. From Figure 10b, the micrographs show an extensive etching composed of dark areas. In presence of $250 \mathrm{ppm}$ of the investigated extract, a protective film is formed on the surface of MS as shown in Figure 10c. This film appears to be smooth and covers the whole surface of the sample without minor flaw. These features confirm the high \%IE obtained for Myrtus communis extract. 


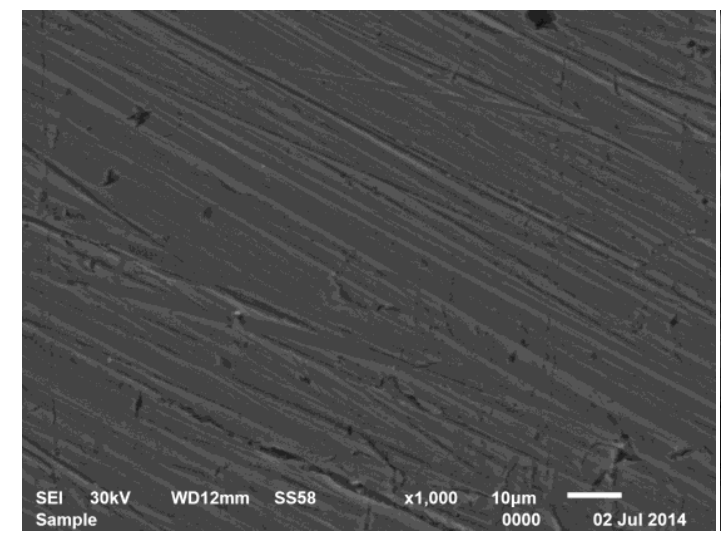

(a) Pure MS

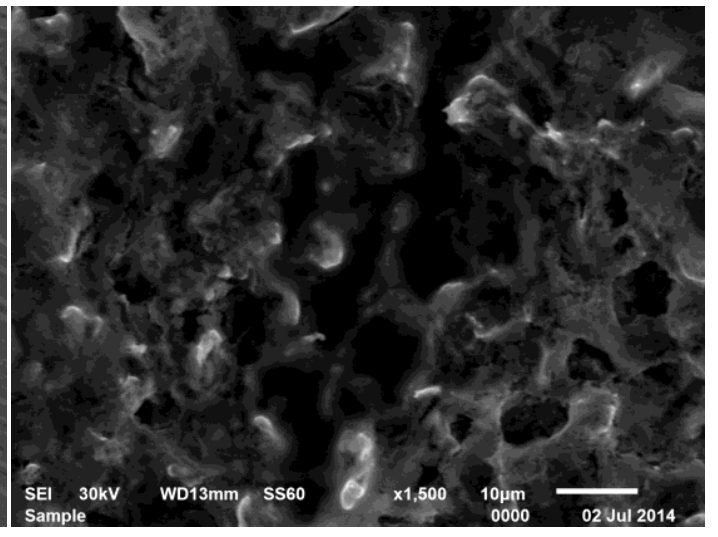

(b) $5 \% \mathrm{NH}_{2} \mathrm{SO}_{3} \mathrm{H}$

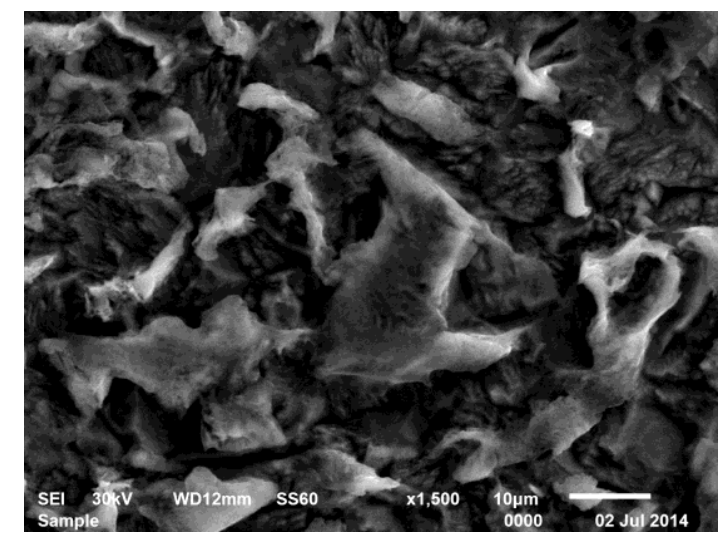

(c) $5 \% \mathrm{NH}_{2} \mathrm{SO}_{3} \mathrm{H}+250$ ppm Myrtus communis

Figure (10): SEM micrographs for MS in absence and presence of $250 \mathrm{ppm}$ of Myrtus communis extract

\section{Energy Dispersion Spectroscopy (EDX) Studies}

The goal of this section was to confirm the results obtained from chemical and electrochemical measurements that a protective surface film of inhibitor is formed on the electrode surface. The corresponding Energy dispersive X-ray (EDX) profile analysis is presented in Figure 11. The EDX survey spectra were used to determine which elements of extract components were present (Table 7) on the electrode surface before and after exposure to the extract solution. For the specimen without exposure to acid solution and inhibitor treatment (Figure 11a), Fe with small traces of $\mathrm{Mn}, \mathrm{Si}, \mathrm{C}$ was detected. It is noticed the existence of the carbon, oxygen peak in the EDX spectra in the case of the sample exposed to the extract, could be attributed to the adsorption of organic molecules at the MS surface. The spectra of Figure 11c shows that the Fe peaks are considerably suppressed relative to the samples prepared in $5 \% \mathrm{NH}_{2} \mathrm{SO}_{3} \mathrm{H}$ solution, and this suppression increases with increasing the extract dose and immersion time. The suppression of the Fe lines occurs because of the overlying extract film. These results confirm those from polarization measurements which suggest that a surface film inhibited the metal dissolution, and hence retarded the hydrogen evolution reaction. This surface film also 
increases the charge-transfer resistance of the anodic dissolution of MS, as present in Figure 6, slowing down the corrosion rate. Therefore, EDX examinations of the electrode surface support the results obtained from chemical and electrochemical methods that Myrtus communis extract is a good inhibitor for MS corrosion in $5 \% \mathrm{NH}_{2} \mathrm{SO}_{3} \mathrm{H}$ solutions.

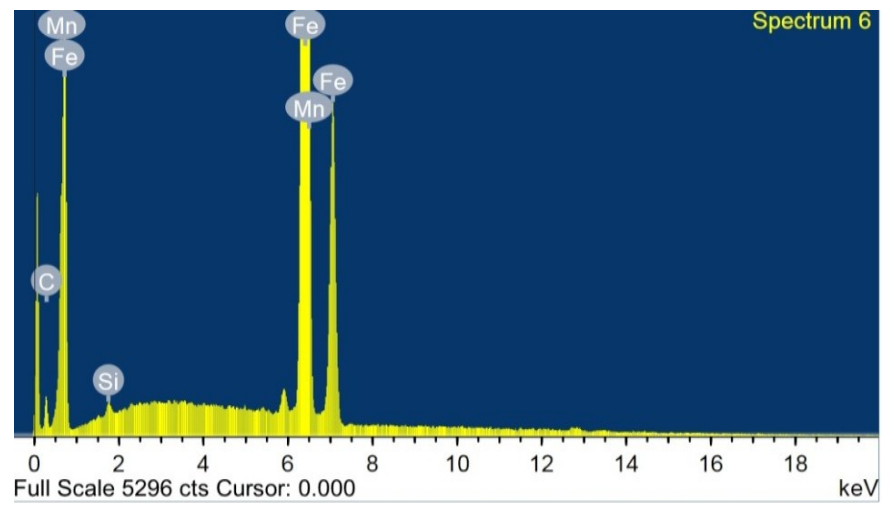

Pure MS

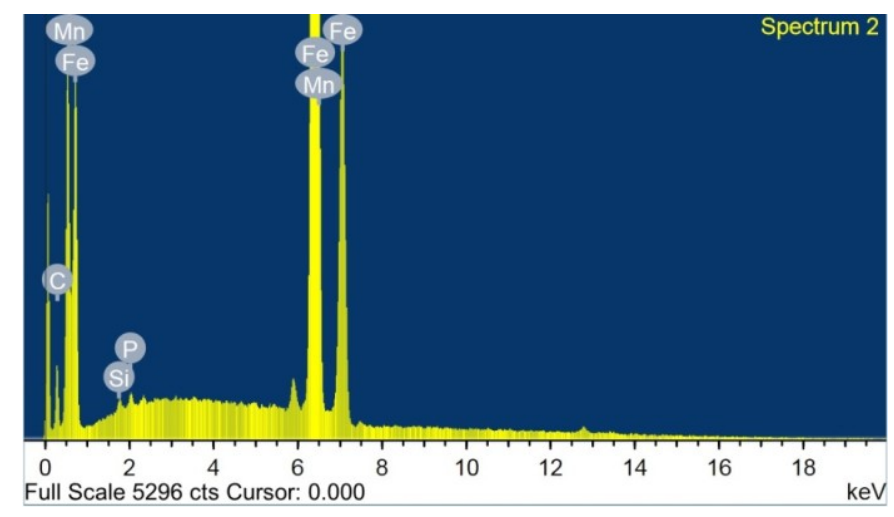

$5 \% \mathrm{NH}_{2} \mathrm{SO}_{3} \mathrm{H}$ only

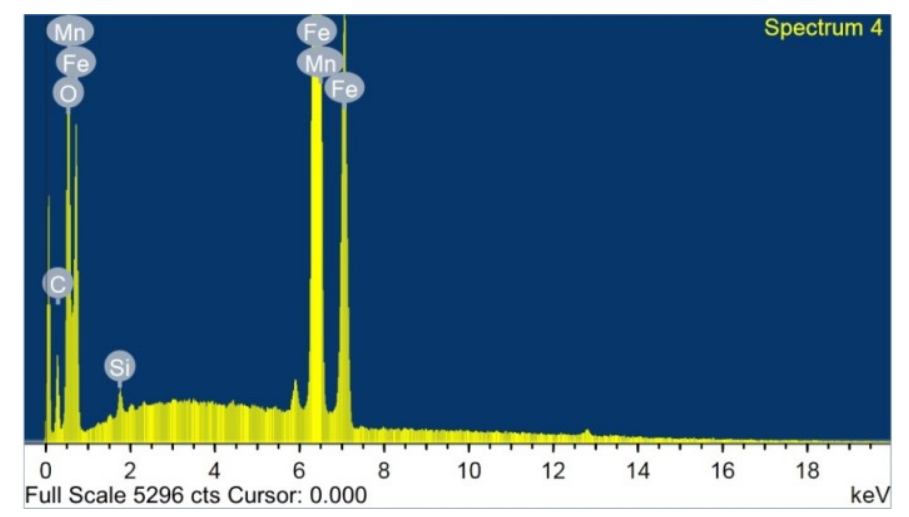

$5 \% \mathrm{NH}_{2} \mathrm{SO}_{3} \mathrm{H}+250$ ppm Myrtus communis

Figure 11. EDX analysis on MS in the absence and presence of $250 \mathrm{ppm}$ of Myrtus extract for 12 hrs immersions.

Table 7. Surface composition (weight \%) of MS after $12 \mathrm{hrs}$ of immersion in $5 \% \mathrm{NH}_{2} \mathrm{SO}_{3} \mathrm{H}$ without and with the optimum dose of the studied inhibitor.

\begin{tabular}{cccccc}
\hline Mass \% & Fe & C & O & Si & Mn \\
\hline Pure & 87.82 & 11.56 & - & 0.38 & 0.76 \\
Blank & 82.26 & 12.63 & - & 0.26 & 0.74 \\
$250 \mathrm{ppm}$ & 65.43 & 16.28 & 20.9 & 0.42 & 0.27 \\
\hline
\end{tabular}




\section{Conclusions}

WL, polarization, impedance and EFM were used to study the corrosion inhibition of MS in $5 \% \mathrm{NH}_{2} \mathrm{SO}_{3} \mathrm{H}$ solutions using aqueous extract of Myrtus communis as an environmentally safe inhibitor. The principle conclusions are:

(i) The acid corrosion of MS is reduced upon the addition of Myrtus extract and IE increases with increasing the plant extract dose.

(ii) A surface film of extract is formed on the electrode surface via electrostatic adsorption.

(iii) EDX observations of the electrode surface showed that a surface film of the extract is formed on the electrode surface. This film retarded the reduction of $\mathrm{H}^{+}$ions and inhibited metal dissolution in hydrochloric acid solutions (mixed-type inhibitor).

(iv) Physisorption is proposed as the mechanism for corrosion inhibition.

(v) The IE obtained from WL data are comparable with those obtained from polarization, EIS and EFM measurements.

\section{References}

1. A.S. Fouda, M.A. El-Morsi, T. Fayed and M. El Said, Res. J. Chem. Sci., 2014, 4, 62.

2. Encyclopedia of Chemical Technology, vol.21, Sulfamic Acid, Wiley Interscience Publication, New York, NY, 1983, pp. 951-957.

3. Testing of Metals for the Process Industries, NACE Publication, London, 1986, pp. 267-268.

4. ASM Handbook. Corrosion: Environments and Industries, ASM International, 1987, 13C, pp. 1140-1144.

5. J.E. Oddo and M.B. Tomson, J. Pet. Technol., 1982, 34, 1583.

6. B. Ridd, T.J. Blakset and D. Queen, Corrosion-1998 (NACE), Paper No. 7, Houston, Texas, 1998.

7. A.K. Satapathy, G. Gunasekaran, S.C. Sahoo, Kumar Amit and P.V. Rodrigues, Corros. Sci., 2009, 51, 2848.

8. A.M. Abdel-Gaber, B.A. Abd-El-Nabey and M. Saadawy, Corros. Sci., 2009, 51, 1038.

9. J.C. da Rocha, N.D.C. Ponciano Gomes and E. D'Elia, Corros. Sci., 2010, 52, 2341.

10. S.S. Abd El-Rehim, H.H. Hassan and M.A. Amin, Mater. Chem. Phys., 2001, 70, 64.

10. A.K. Singh and M.A. Quraishi, J. Mater. Environ. Sci., 2010, 1, 101.

11. A. Ostovari, S.M. Hoseinieh, M. Peikari, S.R. Shadizadeh and S.J. Hashemi, Corros. Sci., 2009, 51, 1935.

12. R.M. Saleh, A.A. Ismail and A.A. El Hosary, Corros. Sci., 1983, 23, 1239.

13. F. Zucchi and I.H. Omar, Surf. Technol., 1985, 24, 391.

14. I.H. Farooqi, M.A. Quraishi and P.A. Saini, Corros. Prev. Control, 1999, 46, 93.

15. A. Peter and S.K. Sharma, Int. J. Corros. Scale Inhib., 2017, 6, no. 2, 112. doi: $\underline{10.17675 / 2305-6894-2017-6-2-2}$ 
16. Ya.G. Avdeev and A.Yu. Luchkin, Int. J. Corros. Scale Inhib., 2013, 2, no. 1, 53. doi: 10.17675/2305-6894-2013-2-1-053-066

17. I. Ithaya Kumar, G. Udayabanu and N.S. Rawat, in: Proceedings of the Seventh European Symposium on Corrosion Inhibitors, Ann. Univ. Ferrara, 1990, 735.

18. A.A. El-Hosary, R.M. Salah and H.A. El-Dahan, in: Proceedings of the Seventh European Symposium on Corrosion Inhibitors, Ann. Univ. Ferrara 1990, 725.

19. M. Kliškic', J. Radoševic, S. Gudic and V. Katalinic, J. Appl. Electrochem., 2000, 30, 823.

20. A. Minhaj, P.A. Saini, M.A. Quraishi and I.H. Farooqi, Corros. Prev. Control, 1999, 46, 32 .

21. K. Srivastava and P. Srivastava, Corros. Prev. Control, 1980, 27, 5.

22. R.M. Saleh, A.A. Ismail and A.A. El Hosary, Corros. Prev. Control, 1984, 31, 21.

23. A.A. El Hosary, R.M. Saleh and A.M. Shams El Din, Corros. Sci., 1972, 12, 897.

24. L. Tang, X. Lie, Y. Si, G. Mu and G. Liu, Mater. Chem. Phys., 2006, 95, 29.

25. L. Tang, G. Murad and G. Liu, Corros. Sci., 2003, 45, 2251.

26. I.N. Putilova, S.A. Balzin and V.P. Barannik, Metallic Corrosion Inhibitors, Pergamon Press, New York, NY, 1960, p. 31.

27. E. Khamis, Corrosion (NACE), 1990, 46, 476.

28. X. Li and L. Tang, Mater. Chem. Phys., 2005, 90, 286.

29. A.A. El-Awady, B. Abd El-Nabey and S.G. Aziz, J. Electrochem. Soc., 1992, 139, 2149.

30. G. Moretti, G. Quartarone, A. Tassan and A. Zingales, Werkst. Korros., 1994, 45, 641.

31. I. Epelboin, M. Keddam and H. Takenouti, J. Appl. Electrochem., 1972, 2, 71.

32. M. Lagrenee, B. Mernari, B. Bounais, M. Traisnel and F. Bentiss, Corros. Sci., 2002, 44, 573.

33. M.A. Quraishi and S.K. Shukla, Mater. Chem. Phys., 2009, 113, 685.

34. A.K. Singh and M.A. Quraishi, Corros. Sci., 2010, 52, 1373.

35. F. Bentiss, C. Jama, B. Mernari, H.E. Attari, L.E. Kadi, M. Lebrini, M. Traisnel and M. Lagrenee, Corros. Sci., 2009, 51, 1628.

36. R. Kanojia and G. Singh, Surf. Eng., 2005, 21, 180.

37. L. Larabi, O. Benali, S.M. Mekelleche and Y. Harek, J. Appl. Surf Sci., 2006, 253, 1371.

38. C.S. Hsu and F. Mansfeld, Corrosion, 2001, 57, 747.

39. P.O. Ameh and N.O. Eddy, Res. Chem. Intermed., 2014, 8, 37.

40. H. Ashassi-Sorkhabi, D. Seifzadeh and M.G. Hosseini, Corros. Sci., 2008, 50, 3363.

41. A. Popova and M. Christov, Corros. Sci., 2006, 48, 3208.

42. Gamry Echem Analyst Manual, Revision 4.2, USA, 2003.

43. R.W. Bosch, J. Hubrecht, W.F. Bogaerts and B.C. Syrett, Corrosion (NACE), 2001, 57, 60.

44. A. Petchiammal, R.P. Deepa, S. Selvaraj and K. Kalirajan, Res. J. Chem. Sci., 2012, 2, 24. 
45. D. Schweinsberg, G. George, A. Nanayakara and D. Steiner, Corros.Sci., 1988, $28,33$.

46. R.W. Bosch, J. Hubrecht, W.F. Bogaerts and B.C. Syrett, Corrosion, 2001, 57, 60.

47. R.W. Bosch and W.F. Bogaerts, Corrosion, 1996, 52, 204.

48. S.S. Abdel-Rehim, K.F. Khalid and N.S. Abd-Elshafi, Electrochim. Acta, 2006, 51, 3269. 